\title{
Determinación de la estructura primaria de la lectina V-2 de semillas de arveja (Pisum sativum L.) y su efecto antibacteriano en Staphylococcus aureus y Escherichia coli
}

\author{
Determination of the primary structure of a lectin V-2 from pea (Pisum sativum L.) \\ seeds and his antibacterial effect on Staphylococcus aureus and Escherichia coli
}

\author{
Alberto Cáceres-Huambo ${ }^{*}$
}

\begin{abstract}
RESUMEN
La lectina V-2 aislada de semillas de Pisum sativum L. ("arveja”) fue purificada mediante cromatografía de exclusión molecular en Sephadex G-75 y cromatografía líquida de alta precisión de fase reversa (HPLC). El análisis en SDS-PAGE de dos dimensiones demostró que la lectina es homogénea con un único spot proteico de $\sim 14 \mathrm{kDa}$ y un punto isoeléctrico de 7,5. Mediante espectrometría de masa (MALDI-TOF) fue confirmado el peso molecular de la lectina mostrando una masa de 14.662,0 Da. La secuencia completa de aminoácidos (estructura primaria) reveló que la lectina V-2 está compuesta de 128 aminoácidos. El estudio comparativo con otras lectinas, mostró que la lectina V-2 tiene mayor homología con la lectina de semillas de Cratylia mollis L. (91,4\%), seguido por la lectina de semillas de Cratylia argentea (61,6\%). De acuerdo al árbol filogenético, la lectina V-2 presenta una aproximación microevolutiva $~ 1.000$ nucleótidos con la lectina de C. mollis. Asimismo, la lectina V-2 mostró acción antibacteriana sobre Escherichia coli y Staphylococcus aureus formando un halo inhibitorio de crecimiento en una concentración de $1 \mathrm{mg}$.

Palabras clave: lectina, Pisum sativum, secuencia de aminoácidos, estructura primaria, efecto antibacteriano.
\end{abstract}

\begin{abstract}
The lectin V-2 from Pisum sativum L. ("arveja”) seeds was purified by Sephadex G-75 molecular exclusion chromatography and reverse phase high performance liquid chromatography (RP-HPLC). Two dimensional SDS-PAGE analyses demonstrated that the purified lectin was homogeneous since it appeared as a single protein spot corresponding to $\sim 14 \mathrm{kDa}$ with an isoelectric point of 7.5. Its molecular weight was confirmed by mass spectrometry (MALDI-TOF) to be 14,662.0 Da. The complete amino acid sequence (primary structure) showed that the lectin V-2 contains 128 amino acids. Comparative studies with other lectins show that it has high homology to the lectin from Cratylia mollis L. (91.4\%), seeds and continued by the lectin from Cratylia argentea $(61.6 \%)$ seeds. According to a phylogenetic tree, the lectin V-2 showed an approximation microevolutionary of $\sim 1,000$ nucleotides with the lectin from $\mathrm{C}$. mollis. Additionally, the lectin $\mathrm{V}$-2 showed antibacterial action on Escherichia coli and Staphylococcus aureus makes an inhibition halo of growth with a concentration of $1 \mathrm{mg}$.
\end{abstract}

Key words: lectin, Pisum sativum, amino acid sequence, primary structure, antibacterial effect.

\section{Introducción}

Las lectinas son glucoproteínas capaces de unirse a azúcares simples o complejos, aglutinar células sanguíneas y se encuentran en tejidos animales, vegetales y microorganismos (Sharon y Lis, 1989; Nagoyama et al., 2002). Las semillas de leguminosas son, particularmente, fuentes ricas de lectinas (Carlini y Grossi-de-Sa, 2002). En los vegetales, la mayoría de las lectinas se encuentran en órganos de reserva (Peumans y Van Damme, 1995; Hivrale e Ingale, 2013), lo que es una evidencia indirecta de su papel como proteínas de defensa.

Mediante investigaciones recientes se comprendió que la mayoría de las lectinas vegetales no solo cumplen un papel en la misma planta, por ejemplo, como una fuente de nitrógeno o como un factor de reconocimiento específico, sino que

\footnotetext{
1 Facultad de Ciencias Biológicas y Agropecuarias de la Universidad Nacional de San Agustín de Arequipa, Arequipa, Perú.

* Autor por correspondencia: acaceresh@ucsm.edu.pe
}

Fecha de Recepción: 21 Abril, 2016.

Fecha de Aceptación: 10 Febrero, 2017.

DOI: $10.4067 / \mathrm{S} 0718-34292017005000006$ 
también interactuarían con glucoconjugados de otros organismos (Peumans y Van Damme, 1995). Las lectinas presentan actividad antiviral, antibacteriana, antifúngica, insecticida y antitumoral (Hudak et al., 2000; Ayouba et al., 1994; Peumans y Van Damme, 1995; Castillo-Villanueva y Abdullaev, 2005).

El presente trabajo de investigación tiene por objetivo determinar la estructura primaria y el efecto antibacteriano de una lectina aislada de semillas de Pisum sativum L. (arveja), pues esta especie es resistente a plagas, así como otras leguminosas, lo que indicaría el papel de la lectina en su mecanismo de defensa.

\section{Materiales y Métodos}

Material vegetal: Semillas de arveja, Pisum sativum $\mathrm{L}$. (Leguminosae), adquiridas en la semillera Rosas S.A.C. de la provincia de Arequipa, Perú.

Extracción salina: De acuerdo a la técnica descrita por Mendoza et al. (2007), $100 \mathrm{~g}$ de semillas enteras fueron trituradas en un molino mecánico hasta la obtención de un material pulverizado. Luego, se tomó $70 \mathrm{~g}$ del material pulverizado con la finalidad de disolverlo en $210 \mathrm{ml}$ (proporción $1: 3 \mathrm{v} / \mathrm{v}$ ) de una solución de $\mathrm{NaCl} 10 \%$ y agitadas por 1 hora a temperatura ambiente, a fin de solubilizar las proteínas. La solución fue filtrada en gasa y centrifugada a $3.000 \mathrm{G}$ por $20 \mathrm{~min} .4^{\circ} \mathrm{C}$ y el sobrenadante obtenido $(120 \mathrm{ml})$ fue dializado en $1 \mathrm{~L}$ de tampón bicarbonato de amonio $\left(\mathrm{NH}_{4} \mathrm{HCO}_{3}\right.$, $0,1 \mathrm{M}), \mathrm{pH} 8,0$, durante 6 horas, realizándose cambios cada 2 horas. La eliminación de sal se comprobó añadiendo gotas de nitrato de plata $\left(\mathrm{AgNO}_{3}, 0,01 \mathrm{~N}\right)$; en presencia de $\mathrm{NaCl}$, la solución adquiere una coloración lechosa. Finalmente, se tomaron 2 alicuotas de $0,1 \mathrm{ml}$ para la determinación de proteínas (método de Biuret) y para la prueba de hemaglutinación. El dializado fue conservado a $4{ }^{\circ} \mathrm{C}$.

Cromatografía de exclusión molecular: Para la purificación proteica se colocó $25 \mathrm{ml}$ del dializado anterior en una columna de exclusión molecular empacada con Sephadex G-75 (1,6 x $100 \mathrm{~cm}$ ), según Toyama et al., (2001). El monitoreo de la corrida cromatográfica fue realizada en un espectrofotómetro a $280 \mathrm{~nm}$; en cada una de las fracciones se detectó la concentración de proteínas mediante el método de Biuret. Para descartar la lectina de otras proteínas se hizo la prueba de hemaglutinación. Las fracciones con actividad hemaglutinante fueron conservadas a $4^{\circ} \mathrm{C}$.
HPLC de fase reversa (RP-HPLC): $20 \mathrm{mg}$ de la fracción con actividad hemaglutinante fue repurificada en una columna $\mu$-Bondapack C18 $(0,78 \times 30 \mathrm{~cm})$ preparativa, previamente equilibrada con ácido trifluoracético 0,1\%, pH 3,5 (Tampón A), acoplada a un sistema de RP-HPLC, según Freire et al. (2001). El sistema cromatográfico empleado fue el HPLC-PDA 991 (Waters) equipado con dos bombas modelo 510/B (Waters) y un inyector automático de muestras U6K con un asa de 2,0 $\mathrm{ml}$ de capacidad (Anexo 2). Inicialmente la elución de la muestra fue realizada por medio de un gradiente lineal (0-100\%) con acetonitrilo $66 \%$ (v/v) (Tampón B). Las fracciones fueron monitoreadas espectrofotométricamente a $280 \mathrm{~nm}$.

Electroforesis bidimensional (2D): La lectina purificada se suspendió en buffer de solubilización (8 M urea, 4\% CHAPS, 70mM DTT, con anfolitos en gradiente $\mathrm{pH}$ lineal $4-7,1,5 \%$ y $0,001 \%$ de azul de bromofenol) y se incubó por $30 \mathrm{~min}$. a temperatura ambiente. Luego se centrifugó a 10.000 rpm por $5 \mathrm{~min}$. Se guardó el sobrenadante para usarlo posteriormente. A $500 \mu \mathrm{g}$ del sobrenadante con la lectina solubilizada se agregó buffer de solubilización. El precipitado obtenido fue depositado en una bandeja de enfocar (cinta de gradientes de $\mathrm{pH}$ inmovilizados). Para la segunda dimensión, la cinta de gradientes fue montada en un gel de poliacrilamida por $1 \mathrm{~h}$ a $200 \mathrm{~V}$. Luego, el gel fue teñido con azul brillante de Coomassie para posteriormente ser escaneado y analizado mediante el Image Master 2D v3.1 Elite software (GE-Amersham Biosciences) (Mendoza-Blanco et al., 2012).

\section{Espectrometría de masa (MALDI-TOF):}

La masa molecular de la lectina purificada se determinó por espectrometría de masa utilizando el sistema MALDI-TOF mediante un Voyager de PRO MALDI-TOF Mass Spectrometry (Applied Biosystems, Foster City, CA, USA). Se mezcló $1 \mu \mathrm{L}$ de la muestra disuelta en TFA $(0,1 \%)$ con $2 \mu \mathrm{L}$ de la matriz ácido 2,5-dihidroxibenzoico (DHB) (Sigma), (disuelta en $60 \%$ acetonitrilo y $0,1 \%$ TFA v/v). La matriz para la calibración correspondiente del equipo, se preparó usando el Kit Calmix 3. Las condiciones de trabajo fueron: voltaje de aceleración $25 \mathrm{kV}$, láser fijo en $2890 \mu \mathrm{J} /$ $\mathrm{cm}^{2}$, retardo $300 \mathrm{~ns}$ y el análisis fue lineal (Smolka et al., 2001).

Estructura primaria: La lectina purificada fue incubada con tripsina a $37^{\circ} \mathrm{C}$ por $8 \mathrm{~h}$. La proteasa 
SV8 de Staphylococcus aureus fue incubada a $37^{\circ} \mathrm{C}$ por $16 \mathrm{~h}$. Los productos de la digestión de estos tratamientos fueron fraccionados por HPLC- de fase reversa usando el sistema Waters PDA 991 y una columna de $\mu$-Bondapack C18. La separación de los péptidos fue realizada en un gradiente de acetonitrilo (0-100\%) en 0,1\% de ácido trifluoracético (v/v) (Mendoza-Blanco et al., 2012). La proteína reducida y carboximetilada (RC-Proteína) se sometió a secuenciación directa en un Secuenciador Automático de Aminoácidos modelo 477 A (Applied Biosystem, USA). La identificación de los PTH (feniltiohidantoina) -aminoácidos se realizó en un PTH Analyzer 120 A (Applied Biosystem, USA). La identificación de los residuos de cisteína se realizó como PTH 14Cys y confirmado por contaje radioactivo.

Estudio de homología secuencial de la estructura primaria y construcción del árbol filogenético: La secuencia completa de aminoácidos (estructura primaria), obtenida del paso anterior, fue comparada en relación con el grado de homología con otras secuencias obtenidas del programa SWISS-PROT (Swiss Institute of Bioinformatics), website: http://www.ncbi.nlm.nih.gov. Para la construcción del árbol filogenético o filograma se usó el programa DNASTAR (ClustalW) que permite obtener las distancias nucleotídicas a partir del alineamiento de las secuencias aminoacídicas ingresadas.

Efecto antibacteriano: El método utilizado fue el de Kirby-Bauer modificado, aplicando la lectina directamente a la placa. Inicialmente, se procedió a coger de cuatro a cinco colonias homogéneas de E. coli y $S$. aureus y con un asa de siembra se transfirió la muestra a un tubo con $10 \mathrm{ml}$ de caldo peptonado; el cultivo fue incubado a $37^{\circ} \mathrm{C}$ hasta que la turbidez coincida con la del estándar $0,5 \mathrm{de} \mathrm{Mc}$ Farland (equivalente a $10^{8}$ bacterias $/ \mathrm{ml}$ ) y dentro de los 15 min después del ajuste de la turbidez, se sumergió un hisopo de algodón, no tóxico, estéril, en la suspensión del inóculo y se rotó varias veces, ejerciendo una presión firme sobre las paredes internas del tubo para quitar el exceso del líquido (Madigan et al., 2003). Seguidamente, se aplicó el inoculó bacteriano en la superficie seca de la placa con agar Triptosa a temperatura ambiente, girando la placa aproximadamente 60 grados se asegura una distribución uniforme del inóculo, luego se tapó la placa y se esperó de 3 a 5 min para que la superficie del agar se seque antes de colocar la lectina. Finalmente, con la ayuda de una espátula estéril se colocó en la parte central de la placa una concentración de $1 \mathrm{mg}$ de lectina en cada una de las placas previamente sembradas con los microorganismos en estudio. Asimismo, se preparó placas control en las que no se les aplicó la lectina. La sensibilidad de la lectina se evaluó mediante la presencia de la formación del halo de inhibición en cada una de las placas.

\section{Resultados y Discusión}

\section{Purificación y caracterización fisicoquímica de la lectina $V-2$}

La purificación de la lectina en la columna de exclusión molecular Sephadex G-75 mostró un perfil cromatográfico (Figura 1) con la presencia de VII picos proteicos, siendo el pico $\mathrm{V}$ el único que mostró actividad hemaglutinante. Para la repurificación se usó la muestra del pico $\mathrm{V}$ y se cargó a una columna de RP-HPLC, donde se obtuvieron dos picos denominados $\mathrm{V}-1$ y V-2 (Figura 2). De estos, el pico V-2 fue el único que presentó actividad hemaglutinante, lo que sugiere que corresponde a la lectina altamente purificada. El pico V-2 fue eluído aproximadamente a los $37 \mathrm{~min}$ y con una concentración de $48 \%$ de tampón B. El pico V-2 es denominado para efectos del estudio como lectina $\mathrm{V}-2$.

Para determinar la masa molecular de la lectina V-2 se usó una electroforesis bidimensional (2D). El

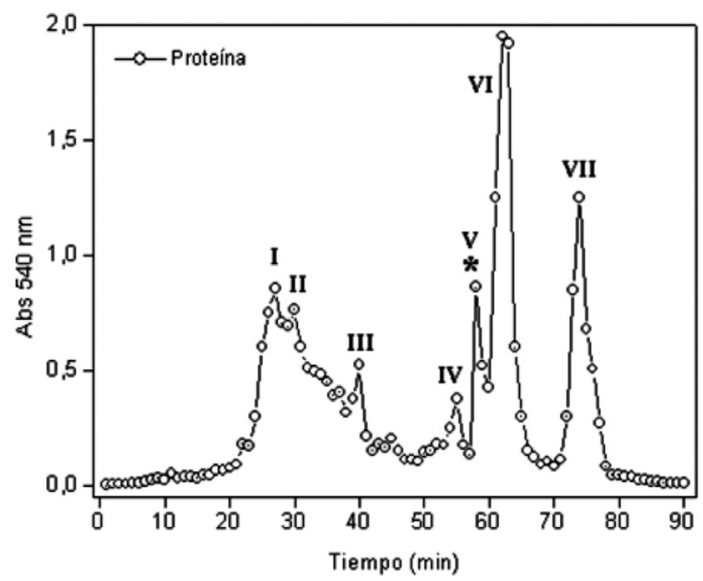

Figura 1. Perfil cromatográfico del extracto salino de semillas de P. sativum en Sephadex G-75. La absorbancia de las fracciones fue monitoreada a $540 \mathrm{~nm}$. El pico V (*) fue el único de los picos que presentó actividad hemaglutinante. 


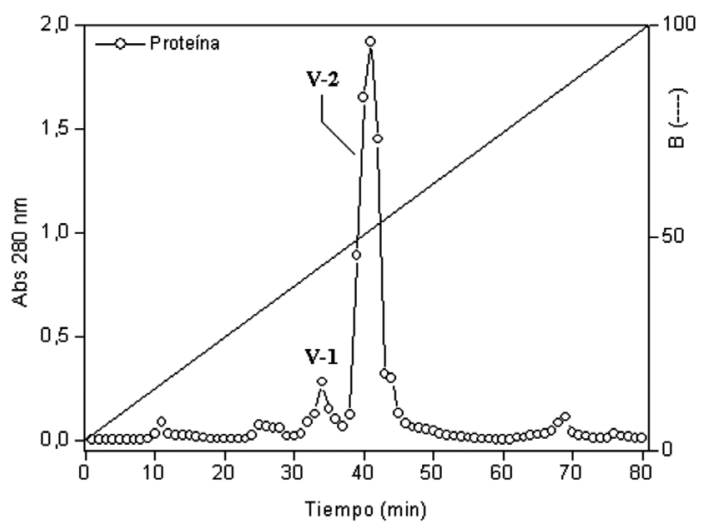

Figura 2. Purificación del pico V por HPLC de fase reversa. La fracción con actividad lectina (hemaglutinante) corresponde a V-2. El monitoreo de la corrida se realizó a $280 \mathrm{~nm}$, siendo las fracciones colectadas a un flujo constante de $1 \mathrm{ml} / \mathrm{min}$.

análisis 2D evidencia que se trata de una proteína de aproximadamente $14 \mathrm{kDa}$ (Figura 3). Asimismo, se encontró que su punto isoeléctrico (pI) se encuentra en torno de 7,5 sugiriendo que se podría tratar de una proteína de carácter ligeramente básico.

Para determinar, en forma más precisa, la masa molecular y constatar el grado de pureza de la lectina V-2 se utilizó la espectrometría de masa en un Voyager DE PRO MALDI-TOF. Los resultados muestran que la lectina V-2 es de naturaleza monomérica, compuesta de una sola

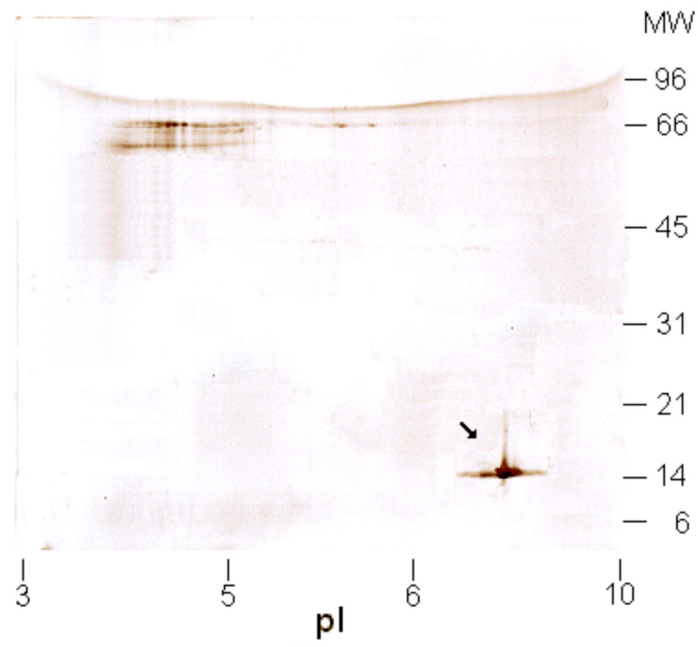

Figura 3. Electroforesis bidimensional (2D) en SDS-PAGE de la lectina V-2. La flecha indica el spot correspondiente a la lectina $\mathrm{V}-2$. El análisis $2 \mathrm{D}$ evidencia que se trata de una proteína de aproximadamente $14 \mathrm{kDa}$ con un punto isoeléctrico $(\mathrm{pI})$ en torno de 7,5. cadena polipeptídica de 14.662,0 Da (Figura 4). Debido a estas características, la lectina V-2 de $P$. sativum es diferente a otras lectinas encontradas en la familia de leguminosas, las que están constituidas generalmente de dos o cuatro cadenas polipeptídicas idénticas de 25 a $30 \mathrm{kDa}$ (Hernández et al., 2005).

\section{Estructura primaria de la lectina V-2}

La estructura primaria de la lectina V-2 fue obtenida por medio de dos pasos: (1) secuenciamiento directo de la proteína reducida y carboximetilada y (2) digestión y secuenciamiento de péptidos de la proteína. Para la determinación de la estructura primaria completa se secuenciaron los péptidos obtenidos de la digestión proteica con proteasa SV8 y tripsina (Figura 5). Los péptidos importantes para la determinación de la estructura primaria de la lectina V-2, fueron: SV8-4, SV8-3, Trp-3 y Trp-07.

La lectina V-2 está compuesta de 128 residuos de aminoácidos: SDSLSFTFDN FRPDQRDLIL QGDAKISSGG DSLQLTKTDT SGKPVRGSVG KALYYTPLHL WDSHTNRLAR FQTTFTFVLS SPTNNRWDGI AFFIAPPETT LPPRSSGGLL GLFVPDNALL NSLNGISA.

En la estructura primaria de la lectina V-2 se observa ausencia del aminoácido cisteína (C) lo que, a su vez, indicaría la falta de puentes disulfuro,

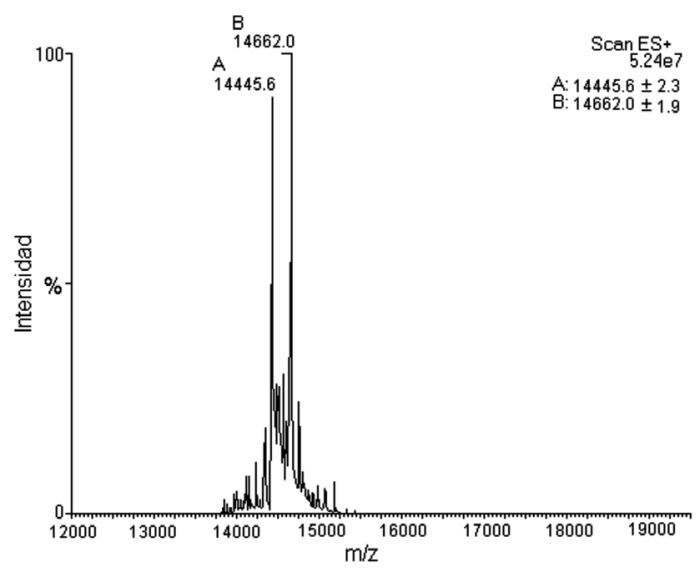

Figura 4. Masa molecular de la lectina V-2 analizada por espectrometría de masa MALDI-TOF. Los análisis muestran que la lectina V-2 es de naturaleza monomérica, compuesta de una sola cadena polipeptídica de $14.662,0 \mathrm{Da}$. El primer pico (A) representa la masa real con una pérdida de aminoácidos producto del bombardeo láser y el segundo pico (B), la masa real. 


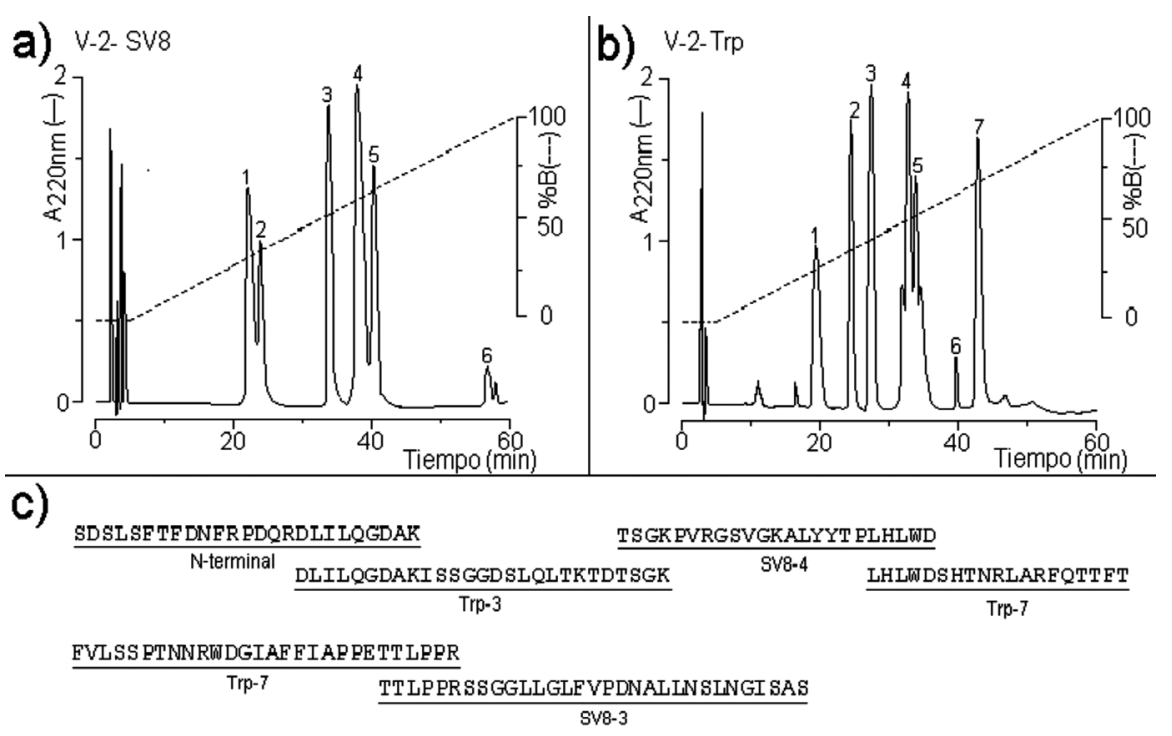

Figura 5. Determinación de la estructura primaria de la lectina V-2. Se obtuvieron péptidos a partir de la digestión enzimática por acción de las proteasas SV8 de Staphyloccocus aureus (a) y Tripsina bovina (b). En c, se muestran las secuencias de aminoácidos obtenidos de la digestión enzimática.

un tipo de enlace covalente que interviene en la estabilización de la estructura terciaria de la proteína. Las cisteínas interaccionan entre sí mediante grupos sulfhidrilo (-SH) formando así los puentes disulfuro (Voet y Voet, 2006).

\section{Estudio de homología secuencial y árbol filogenético de la lectina V-2}

El alineamiento de la estructura primaria demostró que la lectina V-2 tiene alta homología con otras lectinas de la familia Leguminosae. Así tenemos que, la lectina V-2 tiene un 91,4\% de homología con la lectina aislada de semillas de Cratylia mollis (Cramoll), 61,6\% de homología con la lectina aislada de semillas de Cratylia argentea, 50,4\% de homología con la lectina aislada de semillas de Dioclea guianensis, 49,6\% de homología con la lectina aislada de semillas de Dioclea grandiflora y 46,9\% con la lectina aislada de semillas de Canavalia virosa. Los aminoácidos en el recuadro representan regiones de consenso o dominios conservados (Figura 6).

La lectina Cramoll de $C$. mollis, con la cual la lectina V-2 de P. sativum tiene el más alto porcentaje de homología secuencial $(91,4 \%)$, es una lectina de 236 residuos, con cuatro subunidades y capaz de unirse a metales como calcio y manganeso y a la glucosa/manosa (Souza et al., 2003).
Siendo que la lectina V-2 tiene homología con otras lectinas de leguminosas es muy probable que deriven de un antecesor común. Según la clasificación de lectinas vegetales basada en análisis estructural y datos sobre homología secuencial evolucionaria, la lectina $\mathrm{V}-2$ pertenece a la familia de lectinas de leguminosas o tipo L (Peumans et al., 2001; Kumar et al., 2012).

En la construcción del árbol filogenético mediante el programa DNASTAR se observa que la lectina V-2 de arveja, tiene una aproximación microevolutiva de poco más de 1.000 nucleótidos con la lectina aislada de semillas de $C$. mollis (Q39529) y una aproximación casi similar con la lectina aislada de semillas de $C$. argentea (Q39528) (Figura 7). Este hallazgo indica una posible divergencia de la lectina V-2 de la familia Leguminosae en el pasado. El resto de lectinas se encuentran en una aproximación máxima distante de 7.880 nucleótidos.

\section{Efecto antibacteriano de la lectina V-2}

Se formaron halos de inhibición del crecimiento en las placas Petri con cultivos de E. coli y $S$. aureus donde se aplicó $1 \mathrm{mg}$ de lectina (Figuras 8 a y b). Existe ausencia del halo de inhibición en las placas control (sin lectina). En otro estudio, Nair et al. (2013) encontraron que $1 \mathrm{mg} / \mathrm{ml}$ de lectina de $P$. sativum es 
10

20

30

40

50 V-2 SDSLSFTFDNFRPDQRDLILQGDARISSGGDSLQLTKTDTSGRPVRGSVG Q39529 S D S L S F T F D N F R P D Q R D L I L Q G D A R I S S G G D S L Q39528 S D S L S F T F N N F P N S ED L I F Q R A A S I S S N - E TLEL TR I S S S G Q P A T S S V G P58908 A NS L H T F N Q F S Q N P KL L I L Q G D A T T D S D - G N L E L T R V S S S G D P Q G N S V G Q39527 - E A L S F T F T R F V S N Q D E L L L Q G D A L V S S R - G E L Q L T R V E N - G G P P I P H S V G

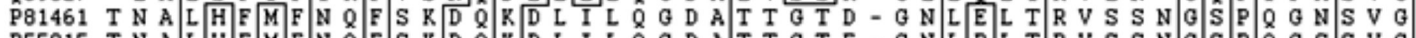

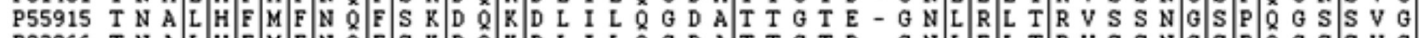
P02866 T N A L P14894 T N A L H F M F F N Q F S K D Q $\mathrm{K}$ D D L I L Q G D A T T G T D - G N L E L T R V S S N G S P Q G S S V G

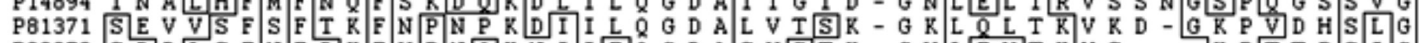

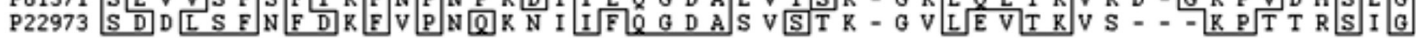

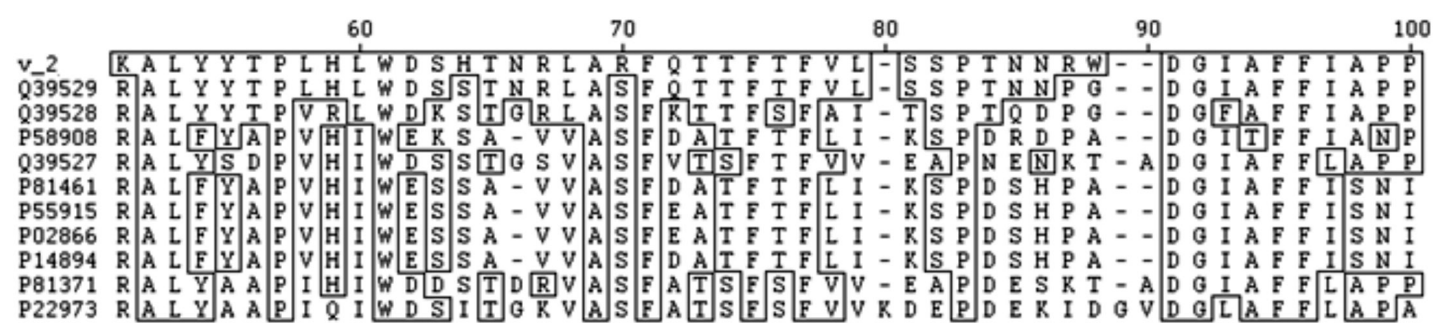

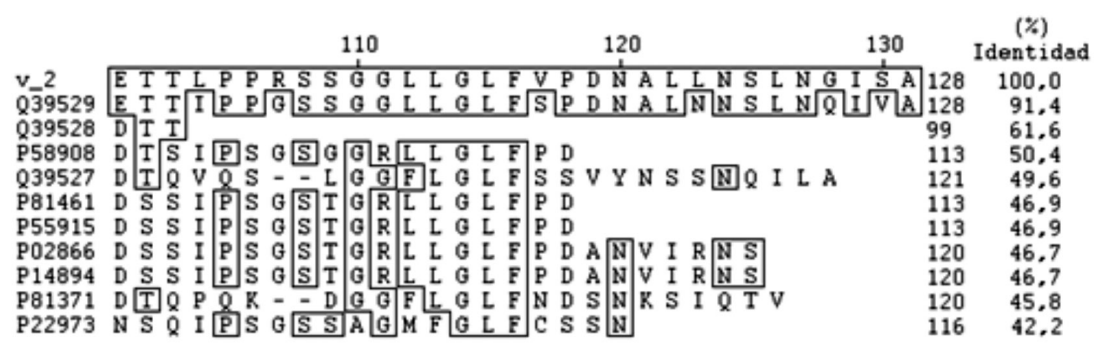

Figura 6. La secuencia de la lectina V-2 muestra entre 91,4-49,6\% de homología o identidad con las secuencias de lectinas: Q39529, que representa a una lectina aislada de semillas de Cratylia mollis; Q39528, que representa a una lectina aislada de Cratylia argentea; P58908, que representa a una lectina aislada de semillas de Dioclea guianensis e Q39527, que representa a una lectina aislada de semillas de Dioclea grandiflora. Las siguientes secuencia de lectinas tienen una homología menor al 50\%: P81461, que representa a una lectina aislada de semillas de Canavalia virosa; P55915, que representa a una lectina aislada de semillas de Canavalia brasiliensis; P02866, que representa a una lectina aislada de semillas de Canavalia ensiformis; P14894, que representa a una lectina aislada de semillas de Canavalia gladiata; P81371, que representa a una lectina aislada de semillas de Vatairea macrocarpa e P22973, que representa a una lectina aislada de semillas de Ulex europaeus.

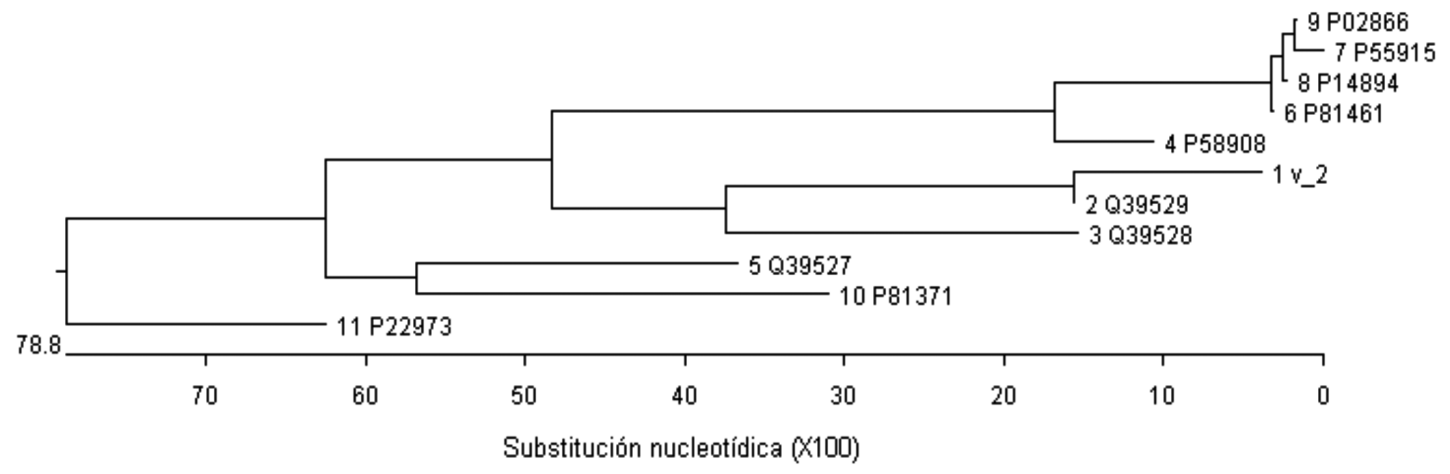

Figura 7. Árbol filogenético de la lectina V-2 de P. sativum mostrando una aproximación microevolutiva de aproximadamente 1.000 nucleótidos con la lectina aislada de semillas de Cratylia mollis (2_Q39529). 


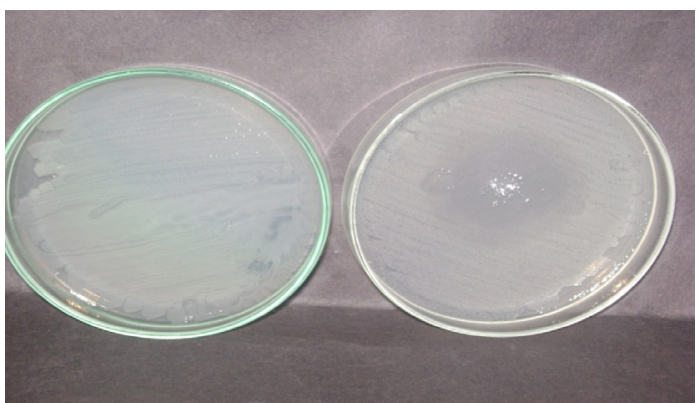

Figura 8a. Efecto antibacteriano de la lectina V-2 (1 mg) sobre Escherichia coli. La placa de la izquierda es el control.

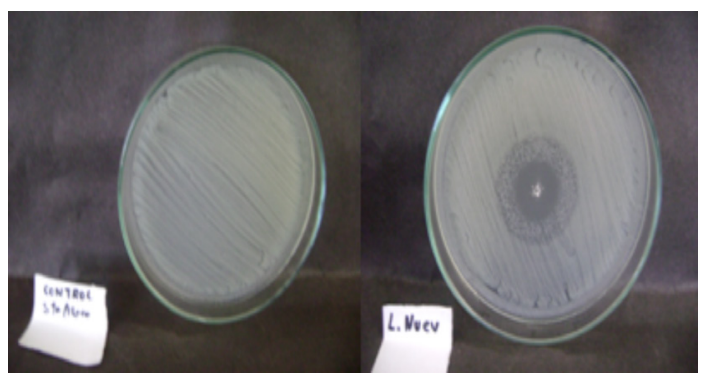

Figura 8b. Efecto antibacteriano de la lectina V-2 (1 mg) sobre Staphyloccoccus aureus. La placa de la izquierda es el control.

capaz de inhibir el crecimiento de E. coli, S. aureus, $B$. subtilis y $P$. aeruginosa. La lectina de P. sativum inhibe el crecimiento bacteriano, sin embargo, no demostró capacidad de matar las bacterias.
Según Schutter y Van Damme (2015) las lectinas vegetales funcionan como receptores de reconocimiento padrón (PRR) que reconocen e interaccionan con los residuos de carbohidratos de los microorganismos patógenos o con los sacáridos derivados de la pared vegetal dañada. Una vez que ocurre la interacción molecular, se desencadena una respuesta inmune intracelular, activando los padrones moleculares asociados al patógeno o microbio (PAMP/MAMP).

\section{Conclusiones}

En el presente trabajo de investigación se determinó la estructura primaria de la lectina V-2 de Pisum sativum. Esta lectina mostró alta homología secuencial con otras lectinas de la familia Leguminosae. Asimismo, se demostró la actividad antibacteriana sobre $E$. coli y $S$. aureus. Futuros estudios van a demostrar otras propiedades biológicas.

\section{Agradecimientos}

Agradezco al Dr. Luis Alberto Ponce Soto del Instituto de Biología de la Universidad del Estado de Campinas, São Paulo, Brasil, por el asesoramiento y por brindarme su apoyo en la infraestructura y equipos para la ejecución del presente trabajo de investigación.

\section{Literatura Citada}

Ayouba, A.; Causse, H.; Van Damme, E.; Peumans, W.; Cambillau, C.; Rougé, P.

1994. Interactions of plant lectins with the components of the bacterial cell wall peptidoglycan. Biochem Syst. Ecol., 22: $153-159$.

Carlini, C.R.; Grossi-De-Sá, M.F.

2002. Plant toxic proteins with insecticidal properties. A review on their potentialities as bioinsecticides. Toxicon, 40 (11): 1515-1539.

Castillo-Villanueva, A.; Abdullaev, F.

2005. Lectinas vegetales y sus efectos en el cáncer. Revista de Investigación Clínica, 57 (1): 55-64.

Freire, M.; Machado, O.; Smolka, M.; Marangoni, S.; Novello,

J.; Macedo, M.

2001. Isolation and characterization of isolectins from Talasia esculenta seeds. J. Protein. Chem, 20 (6): 495-500.

Hernández, P.; Pérez, E.; Martínez, L.; Ortiz, B.; Martínez, G. 2005. Las Lectinas Vegetales como modelo de estudio de las Interacciones Proteína-Carbohidrato. REB, 24 (1): 21-27.

Hivrale, A.U.; Ingale, A.G.

2013. Plant as a plenteous reserve of lectin. Plant Signaling \& Behavior 8 (12). DOI: 10.4161/psb. 26595.
Hudak, K.; Wang P.; Tumer, N.

2000. A novel mechanism for inhibition of translation by pokeweed antiviral protein: depurination of the capped RNA template. RNA, 6: 369-380.

Kumar, K.K.; Chandra, K.L.P.; Sumanthi J.; Reddy, G.S.; Shekar, P.C.; Reddy, B.V.R.

2012. Biological role of lectins: A review. Journal of Orofacial Sciences, 4 (1): 20-25.

Madigan, V.T.; Martinko J.M. Parker J.

2003. Brock: Biología de los microorganismos, $10^{\text {a }}$ edición, Editorial Pearson Educación, Madrid, España. 1096 pp.

Mendoza-Blanco, Werner; Ponce-Soto, Luis A.; Marangoni, Sergio.

2012. Purification and primary structure of a lectin from Buddleja coriacea seeds. SCIÉNDO, 15 (1): 81-88.

Mendoza, W.; Gandolfo, L.; Ponce, L.; Novello, J. y Marangoni S. 2007. Estudios estructura y función de una lectina aislada de semillas de Caesalpinia spinosa Kuntze (tara). Idesia, 25 (2): 49-58.

Nagoyama, C.; Lalojo, F.M.; Genoves, M.I.

2002. Nutritional significance of lectins and enzyme inhibitors from legumes. J Agric. Food. Chem, 50 (22): 6592-6598. 
Nair, S.S.; Madembil, N.C.; Nair, P.; Raman, S.; Veerabadrappa, S.B. 2013. Comparative analysis of the antibacterial activity of some phytolectins. International Current Pharmaceutical Journal, 2 (2): 18-22.

Peumans, W.; Van Damme, E.J.M.; Barre, A.; Rougé, P. 2001. Classification of plant lectins in families of structurally and evolutionary related proteins. Adv. Exp. Med. Biol., 491: 27-54.

Peumans, W.; Van Damme E.

1995. Lectin as plant defense proteins. Plant Physiol, 109: 347-352.

Sharon, N.; Lis, H.,

1989. Lectins as cell recognition molecules. Science, 246 (4927): 227-234.

Schutter, K.; Van Damme, E.J.M.

2015. Protein-Carbohydrate Interactions as Part of Plant Defense and Animal Immunity. Molecules, 20: 9029-9053.
Smolka, M.B.; Zhou, H.; Purkayastha, S.; Aebersold, R. 2001. Optimization of the isotope-coded affinity tag-labeling procedure for quantitative proteome analysis. Anal. Biochem, 297: 25-31.

Souza, G.A.; Oliveira, P.S.L.; Trapani, S.; Santos, A.C.O.; Rosa, J.C.; Laure, H.J.; Faça, V.M.; Correia, M.T.S.; Tavares, G.A.; Oliva, G.; Coelho, L.C.B.B.; Greene, L.J.

2003. Amino acid sequence and tertiary structure of Cratylia mollis seed lectin. Glycobiology, 13 (12): 961-972.

Toyama, M.; Carneiro, E.; Marangoni, S.; Amaral, M.; Velloso,

L. y Boschero, A.

2001. Isolation and characterization of a convulxin-like protein from Crotalus durissus collilineatus venom. $J$. Prot. Chem, 20 (7): 585-591.

Voet, D.; Voet, J.

2006. Bioquímica. Ed. Médica Panamericana S.A., Buenos Aires, Argentina. 1776 pp. 